\title{
Mechanical Performance of Hybrid Carbon/Fiberglass Composite Laminates Reinforced with Nanoclay
}

\author{
G. ONER ${ }^{a, *}$, H.Y. UNAL ${ }^{b}$ AND Y. PEKBEY ${ }^{b}$ \\ ${ }^{a}$ University of Atatürk, Automotive Program, Vocational School, 25240 Erzurum, Turkey \\ ${ }^{b}$ University of Ege, Department of Mechanical Engineering, Bornova, 35100 İzmir, Turkey
}

\begin{abstract}
The objective of this study was to produce the hybrid carbon/fiberglass composite laminates, to characterize their mechanical properties under room temperature and to evaluate the effect of nanoclay addition into epoxy matrix on the mechanical properties of the hybrid composites. During fabrication of fiber reinforced polymer composites, the organo modified nanoclay $(0 \%, 0.5 \%, 0.75 \%$, and $1.25 \%$ of nanoclay reinforcement by weight) was mixed with epoxy system using an ultrasonic mixer. The produced matrix was then applied onto fibers by using hand layup method. Mechanical tests were performed to investigate the effect of nanoclay content on tensile and flexural properties of the fabricated hybrid carbon/fiberglass composites. The tensile and three point bending tests were performed according to ASTM D3039 and ASTM D7264, respectively, to measure the highest tensile strength, modulus of elasticity and bending modulus of the hybrid laminates. Experimental results show that the tensile and flexural performance of hybrid carbon/fiberglass composites was changed with the nanoclay content.
\end{abstract}

DOI: 10.12693/APhysPolA.134.164

PACS/topics: nanoclay, tensile strength, hybrid laminate, flexural performance

\section{Introduction}

Epoxy resin systems are progressively used as matrices to form advanced multifunctional composite materials in which a high specific strength is necessary. The idea of hybridization, as a method for changing the mechanical properties of fibre reinforced composites, has continued to improve. Such mechanical properties as modulus or strength of composites can be affected by adding into it the nanoparticles.

For this reason, the primary aim of many researchers is to ensure epoxy with higher mechanical and dynamic performance, which are necessary and requested in practice. A comprehensive studies were performed to study the effect of low and high aspect ratio nanoparticles on the composites. These additives have already shown their capability to increase the strength, toughness and to improve the thermo-mechanical properties of polymers.

Still, so far there are problems of distributing the nanoparticles homogeneously in the matrix. Carbon and glass fibre reinforced polymer hybrid composites are widely used in many high technology fields of engineering because of their advantageous properties, such as high stiffness, high strength, and low weight. There are many studies related to mechanical properties of hybrid composite laminates in the literature, but very few published investigations are found, focused on the design of hybrid composite laminates reinforced with nanoparticles.

Sarasini et al. [1] presented the low-velocity impact behavior of hybrid laminates reinforced with woven aramid and basalt fabrics and manufactured by resin transfer

*corresponding author; e-mail: galar@atauni.edu.tr moulding. Koricho et al. [2] studied the behavior of pristine and nano-/micro-modified GFRP composites under quasi-static indentation and at low velocity impact tests.

Kalantari et al. [3] investigated the effect of hybridization on the flexural strength of carbon/glass fibre reinforced epoxy hybrid composites with the aim of elucidating the mechanisms behind the hybrid effect. Pathak et al. [4] improved the mechanical properties of polymer composites with graphene oxide used as one of the fillers for the development of carbon fiber/graphene oxide-epoxy hybrid composites.

Öner et al. [5], in their experimental work, added 1 and $1.25 \mathrm{wt} . \%$ of carbon nanotubes into the epoxy matrix and compared the properties of the composites with those of the non-modified composite. Plain weave E-glass fabrics were used for producing the composite plates. Impact properties were investigated at room temperature.

Unal and Pekbey [6] investigated concentration ratio of nano filler on impact behavior of composite materials in the low velocity impact tests. Hine et al. [7] compared the properties of self-reinforced polyamide 12 /carbon fibre hybrid composites made by three different hybridization routes, termed intra-yarn, intra-layer and inter-layer. The tensile modulus and strength were significantly improved over the pure self-reinforced polyamide sheet, although the tensile failure strain was significantly reduced from $10 \%$ to $<2 \%$. In bending, however, the modulus and strength were again significantly improved without compromising the ductility.

According to literature survey, there is no sufficient investigation of mechanical performance of hybrid composites containing nano particles. In this study, the mechanical behavior of carbon and glass fibre reinforced hybrid composites with nano particles, under tension and flexural loading was investigated experimentally to define the 
flexural modulus and strength. The effect of nanoclay on the tensile and flexural tests was also reported for hybrid composites.

\section{Materials and experimental procedure}

A standard epoxy resin with carbon $\left(245 \mathrm{~g} / \mathrm{m}^{2}\right)$ and Eglass $\left(200 \mathrm{~g} / \mathrm{m}^{2}\right)$ fibers were used. The organo modified nanoclay used in this study was supplied by Esan, Eczacıbaşı. The addition of nanoclay into the epoxy matrix was performed by ultrasonic cavitation mixing. Then the hybrid combinations were formed.

Since the properties of nanocomposites may be affected by the interface area, it is important to distribute nanoclay homogeneously in the epoxy resin. The process of dispersion of nanoclay in the epoxy matrix was shown in
Fig. 1. It was performed by using an ultrasonic mixer (Hielscher UP400S, shown in Fig. 1a). Hielscher UP400S supplies sound waves to break up the agglomerates in the liquid epoxy/agglomerate mixture by sonication, as shown in Fig. 1c. The sound waves were applied to mixture for at least $30 \mathrm{~min}$. The temperature of the mixture was followed using laser thermometry. When temperature of the mixture approached $50^{\circ} \mathrm{C}$, the sonication was stopped until temperature would decrease. After sonication process the hardener was added to the mixture and the mixture was stirred for the extra $10 \mathrm{~min}$.

A hand layup method was used in the fabrication of the composite laminates. Prepared resin was poured on carbon and glass fiber mats, which are shown in Fig. 2a and $b$, respectively.
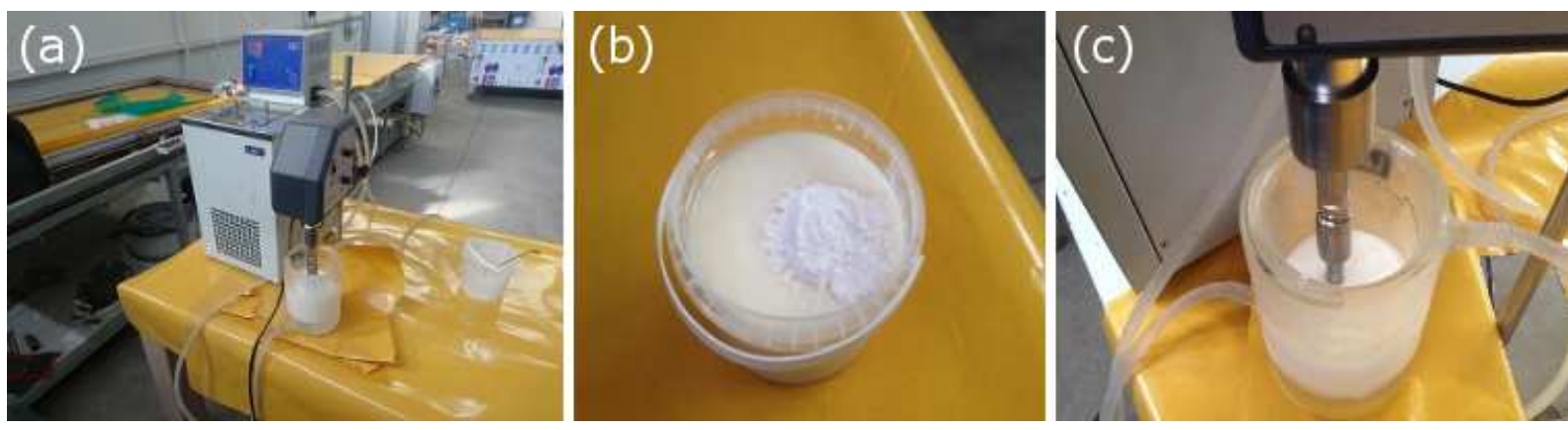

Fig. 1. The dispersion of nanoclay in the epoxy matrix, (a) ultrasonic mixer, (b) addition of nanoclay into epoxy, (c) dispersion of nanoclay.
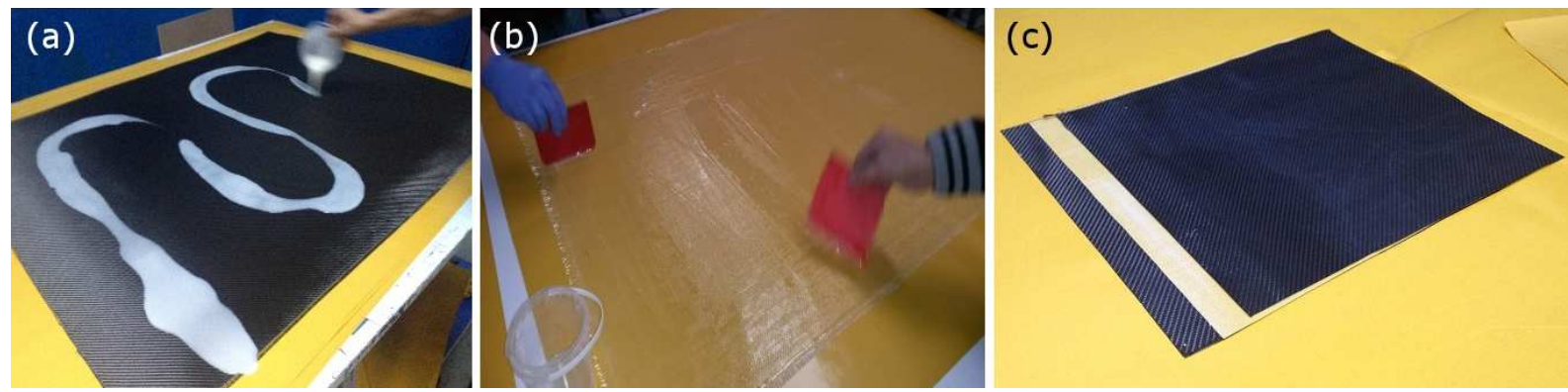

Fig. 2. Preparation of laminates (a) carbon prepreg production, (b) glass prepreg production, (c) hybrid plate stacking sequence.

Resin impregnated fabrics were left to dry at room temperature for 10 days. In this way the production of prepreg carbon and glass fabrics was completed. After 10 days semi-finished fabrics were added up, wrapped with fireproof film and, after that, were placed inside a hydraulic hot press.

Firstly fabrics were exposed to 10 bar pressure. After that the temperature was raised from room temperature to $125^{\circ} \mathrm{C}$. Plate was kept for one hour at these conditions. After one hour heater was turned off, but the pressure was still applied. Plate was slowly brought to room temperature.

Composite plates were cut using water jet cutter because composite plates were sensitive to machining. Hy- brid composites had carbon fabrics outside and E-glass fabrics inside. The carbon fabrics contained five layers, placed at each side of the plate and the E-glass core had also five layers, as shown in Fig. 3. In total 15 layers of fabrics were used and total thickness of $3 \mathrm{~mm}$ was achieved.

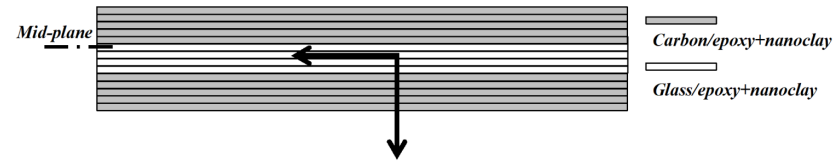

Fig. 3. Configuration of hybrid composite laminate [3]. 

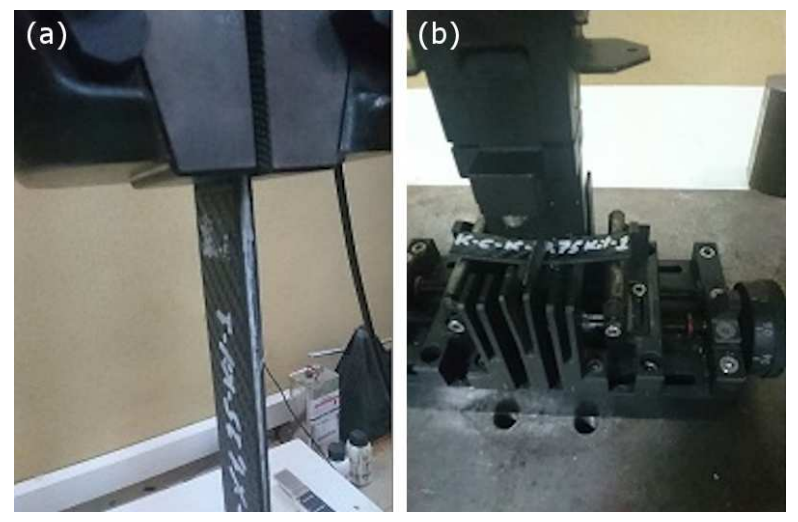

Fig. 4. Test setup of composite specimens, (a) tensile test, (b) three point bending test.

A minimum of three samples were tested in both, the tensile tests and the flexural tests. Samples had rectangular dimensions of $250 \times 25 \mathrm{~mm}^{2}$ for tensile tests and $76.8 \times 14 \mathrm{~mm}^{2}$ for flexural tests, with thickness of $3 \mathrm{~mm}$. Tensile tests and three-point flexural tests were carried out according to ASTM D3039-17 [8] and ASTM D726415 [9] standard, respectively, using Schimadzu universal tester; model Autograpgh, equipped with a $100 \mathrm{kN}$ loadcell (see Fig. 4). The average values were recorded.

In tensile tests the loading was performed in displacement control mode using a $2 \mathrm{~mm} / \mathrm{min}$ velocity. Composite tabs were bonded to the ends of the tensile test specimens using adhesive to facilitate gripping. The ultimate tensile strength of each sample was detected from the maximum load supported by specimen before failure had occurred. Flexural tests were carried out at room temperature using three-point flexural test procedure and by applying a cross-head speed of $1 \mathrm{~mm} / \mathrm{min}$. The distance between the supports was kept at $64 \mathrm{~mm}$, as given in the standard. The ultimate flexural strength of each specimen was determined using the maximum load reached before failure.

\section{Results and discussion}

Results of tensile and flexure testing for the pure epoxy matrix composite and three nanoclay containing composites $(0.5,0.75$ and 1.25 wt.\%) are shown in Fig. 5 and Fig. 6, respectively. From figures it can be noted that nanoclay addition to epoxy has resulted in a positive effect on hybrid composites. When the hybrid composite without nanoclay is compared with the composite with the nanoclay addition to epoxy, it can be detected that nanoclay addition increases the tensile and flexural strength significantly.

The highest tensile test results were achieved after addition of 0.75 wt. $\%$ of nanoclay to hybrid plate. Addition of 0.75 wt.\% of nanoclay into epoxy increases Young's modulus from 66991 to $68066 \mathrm{MPa}$ (an increase of 2\%), which is most likely due to appropriate dispersion of the nanoclay and improved interaction between the filler and
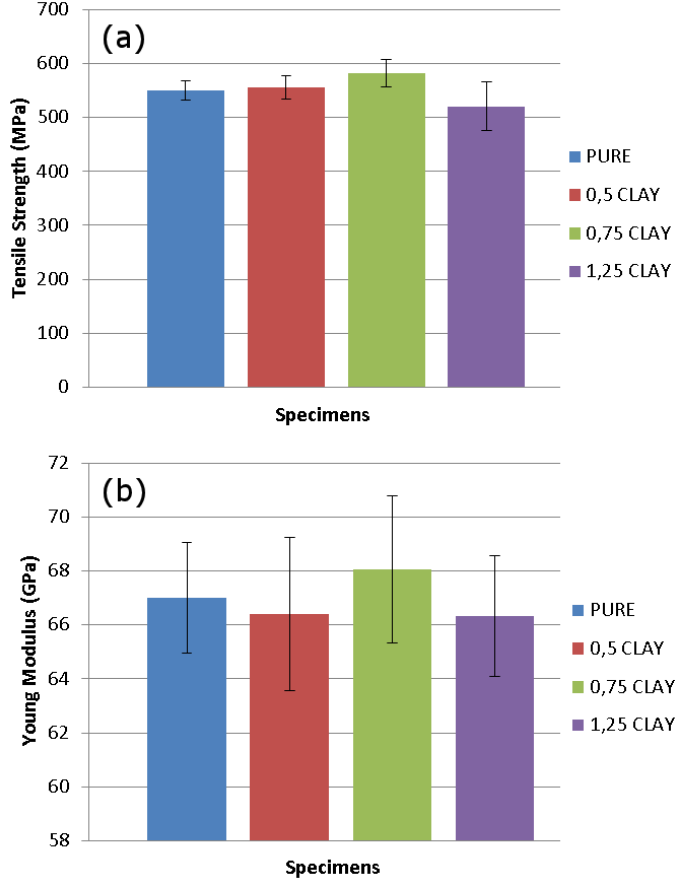

Fig. 5. Tensile tests results, (a) tensile strength, (b) Young modulus.
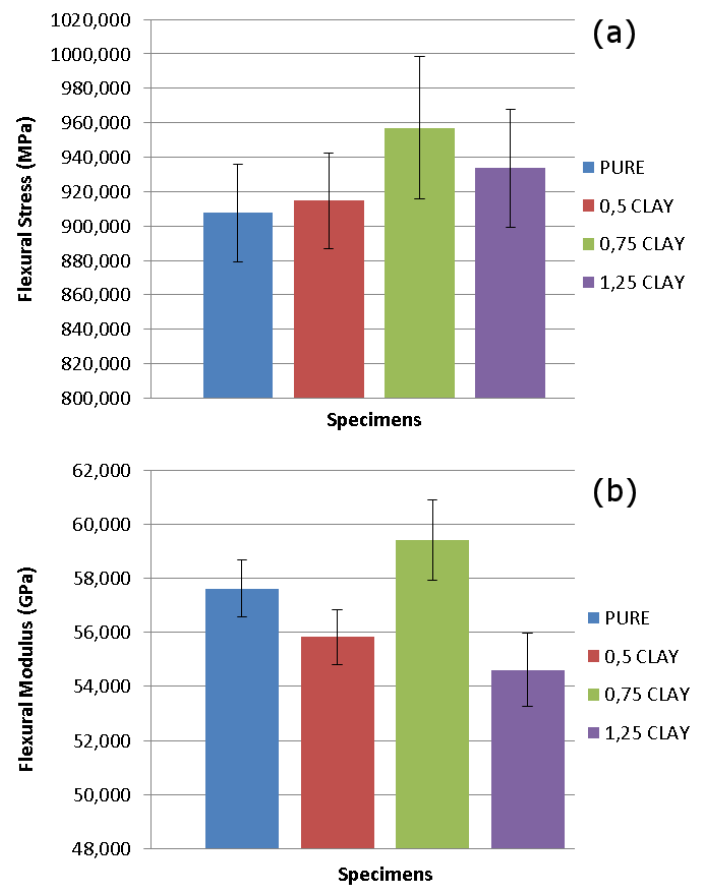

Fig. 6. Flexural test results, (a) flexural stress, (b) flexural modulus.

the matrix. In the specimen containing 0.75 wt. $\%$ nanoclay the tensile loading resulted in the largest strength improvement of about $6 \%$, from $550 \mathrm{MPa}$ in the control group to $582 \mathrm{MPa}$. 
It was found that the lowest tensile strength and Young's modulus occurred in composites containing 1.25 wt. $\%$ of nanoclay. A decrease of $5 \%$ in tensile strength was observed in hybrid composite with 1.25 wt. $\%$ of nanoclay.

The addition of 0.5 wt.\% of nanoclay resulted in smaller gains, since the improvements in tensile strength was still $1 \%$ greater than that of the pure samples. It should be also noted that the composite with 0.5 wt.\% of nanoclay has shown a lower Young's modulus compared to pure specimen.

According to experimental data, flexural modulus for the pure epoxy containing specimen was measured to be about $57610 \mathrm{MPa}$ and the average flexural strength was 907.541 MPa. The best results were acquired with the addition of $0.75 \mathrm{wt} . \%$ of nanoclay, when the flexural modulus increased from 57610 to $59404 \mathrm{MPa}$ (an increase of $3 \%$ ), due to an appropriate dispersion of the nanoclay.

In addition, the highest flexural strength was also achieved in the hybrid composite containing 0.75 wt.\% of nanoclay. The flexural strength of this specimen has shown about $6 \%$ improvement, from $907 \mathrm{MPa}$ in the control group to $957 \mathrm{MPa}$. The flexural strength has also increased with the addition of nanoclay into epoxy of hybrid composites, compared to pure specimen. The smallest change in flexural strength was observed for the specimen containing $0.5 \mathrm{wt} . \%$ of nanoclay. With the addition of more than 0.75 wt.\% of nanoclay, i.e. 1.25 wt.\%, the flexural modulus of the hybrid composite decreased compared to pure specimen.

\section{Conclusions}

This study was focused on the manufacturing and the mechanical performance of hybrid carbon/glass composite laminates. The effects of nanoclay on the hybrid laminates were investigated. It was detected that the presence of nanoclay in the epoxy has changed the mechanical performance of the hybrid laminates. The addition of nanoclay has been shown to improve the tensile and flexural performance of hybrid composites.
It was obtained that the sample containing 0.75 wt. $\%$ of nanoclay had the highest tensile and flexural strength and modulus values among studied nanoclay compositions. This investigation shows the possibility of improving the tensile and flexural strength of carbon/glass epoxy hybrid composites by choosing a suitable nanoclay addition to epoxy.

\section{Acknowledgments}

This research has been supported by the Scientific Research Project of Atatürk University of Turkey (BAP). Project number: BAP 2016/139.

\section{References}

[1] F. Sarasini, J. Tirillò, M. Valente, L. Ferrante, S. Cioffi, S. Iannace, L. Sorrentino, Mat. Des. 49 , 290 (2013).

[2] E.G. Koricho, A. Khomenko, M. Haqa, L.T. Drzal, G. Belingardi, B. Martorana, Compos. Struc. 134, 789 (2015).

[3] M. Kalantari, C. Dong, I.J. Davies, Compos. Part B: Eng. 102, 100 (2016).

[4] A.K. Pathak, M. Borah, A. Gupta, T. Yokozeki, S.R. Dhakate, Compos. Sci. Technol. 135, 28 (2016).

[5] G. Öner, H.Y. Unal, Y. Pekbey, Journal of Çukurova University of Engineering - Architecture Faculty 31(2), 87 (2016).

[6] H.Y. Unal, Y.Pekbey, 2nd International Conference of Mechanics of Composites, 2016.

[7] P.J. Hine, M.J. Bonner, I.M. Ward, Y. Swolfs, I. Verpoest, Compos. Part A: Appl. Sci. Manuf. 95, 141 (2017).

[8] ASTM D3039 / D3039M-17, Standard Test Method for Tensile Properties of Polymer Matrix Composite Materials, ASTM International, West Conshohocken, PA 2017.

[9] ASTM D7264 / D7264M-15, Standard Test Method for Flexural Properties of Polymer Matrix Composite Materials, ASTM International, West Conshohocken, PA 2015. 